\title{
A "Morada" como constelação e encruzilhada: estética e política em experiências audiovisuais
}

\author{
The "Home" as constellation and crossroad: aesthetics and politics on \\ audiovisual experiences
}

La "Morada" como constelación y encrucijada: estética y política en las experiencias audiovisuales

\author{
Scheilla Franca de SOUZA $^{1}$ \\ Jorge CARDOSO FILHO²
}

\begin{abstract}
Resumo
Este artigo propõe uma reflexão acerca de duas formas de abordagem da experiência estética - aqui mais especificamente do audiovisual - que permitem miradas fabulatórias de lampejos, aparições e incorporações multitemporais: a constelação e a encruzilhada. Para tanto, partimos de uma constelação de obras audiovisuais em cruzo entre vida/arte - realizadas na pandemia e também além deste contexto -, que têm muito forte o signo da morada, da relação pela intimidade familiar/comunitária. Contemplando este miríade estelar, suas relações e os cruzamentos de seus pontos estelares nos propomos a, partindo das performances, pelas frestas, pontuar alguns gestos de continuidade e ruptura nos corpos audiovisuais - nos corpos da cena e em cena - fabulando algumas de suas implicações e legados estéticos e políticos para o universo audiovisual porvir.
\end{abstract}

Palavras-chave: Audiovisual; Constelações; Encruzilhada; Experiência;

Performance.

\footnotetext{
${ }^{1}$ Realiza estágio de pós-doutorado no PPGCOM-UFRB sob supervisão do Prof. Dr. Jorge Cardoso Filho. Pesquisadora integrante do Grupo de Estudos em Experiência Estética, Comunicação e Artes (GEEECA/UFRB) desde 2018. Doutora em Comunicação e Cultura Contemporâneas pelo POSCOMUFBA - E-mail: scheillafranca@gmail.com - ORCID: 0000-0002-7883-1424.

2 Docente do Centro de Artes, Humanidades e Letras da Universidade Federal do Recôncavo da Bahia e do POSCOM-UFBA. Doutor em Comunicação Social-UFMG - E-mail: cardosofilho.jorge@gmail.com ORCID: 0000-0002-4276-934X.
} 


\begin{abstract}
This paper proposes a reflection on two ways of approaching the aesthetic experience - here more specifically the audiovisual one - that allow seeing flashes, appearances and multitemporal incorporations: the constellation and the crossroads. For this we start from a constellation of audiovisual works in a cross between life/art - made during the pandemic and also beyond this context -, which have a very strong sign of housing, of relationship through family/community intimacy. Contemplating this stellar myriad, its relationships and the intersections of its stellar points, we propose, from the performances, through the gaps, to point out some gestures of continuity and rupture in the audiovisual bodies - in the bodies of the scene and in the scene fabulating some of its implications and aesthetic and political legacies for the coming audiovisual universe.
\end{abstract}

Keywords: Audiovisual; Constellations; Crossroads; Experience; Performance.

\title{
Resumen
}

Este artículo propone una reflexión sobre dos formas de abordar la experiencia estética - aquí más concretamente la audiovisual - que permiten miradas de flashes, apariciones e incorporaciones multitemporales: la constelación y la encrucijada. Para ello partimos de una constelación de obras audiovisuales en un cruce entre vida / arte, realizadas en la pandemia y también más allá de este contexto - que tienen un signo muy fuerte de vivienda, de relación a través de la intimidad familia/comunidad. Contemplando esta miríada estelar, sus relaciones y las intersecciones de sus puntos estelares, nos proponemos, a partir de las performances, mediante de los huecos, señalar algunos gestos de continuidad y ruptura en los cuerpos audiovisuales - en los cuerpos de la escena y en los escena - fabulando algunas de sus implicaciones y legados estéticos y políticos para el universo audiovisual venidero.

Palabras clave: Audiovisual; Constelaciones; Encrucijadas; Experiencia; Performance.

\section{Introdução}

Interessa-nos neste artigo pensar, através do desenho inicial 3 de uma constelação audiovisual em encruzilhada, as performances de ruptura e continuidade no audiovisual durante a pandemia de Covid-19 e também em outros contextos, com a presença do familiar/comunitário. Isto porque o fazer comum, familiar e doméstico salta em nossa percepção dialógica entre proposições. Este gesto de contemplação desta constelação de partida permite ainda a fabulação de um universo audiovisual

\footnotetext{
3 Uma versão inicial deste trabalho foi apresentada sob o título de "Encruzilhadas Audiovisuais: Experiências Estéticas em Tempos de Pandemia e suas Implicações Políticas" no Intercom 2021. Ver SOUZA e CARDOSO FILHO (2021).
} 
porvir, pós-pandêmico, a partir do comum que brota destas produções, da interação entre elas e nosso olhar, com relações multitemporais e de incorporações.

As relações entre intimidade, comunidade, partilha no diálogo das artes com o audiovisual, entre vida cotidiana e ficção, constituem corpos em cena e corpos da cena (BOGADO; ALVES JUNIOR; DE SOUZA, 2020) de muitas experiências propostas ao longo dos tempos, sobretudo, se olharmos para o contexto brasileiro cinematográfico recente, de maneira mais acentuada na segunda década do século XXI, com a emergência de mais produções fílmicas voltadas ao coletivo.

Na pandemia, quando é necessário o recolhimento às casas, à intimidade, à vida mais restrita ao seu entorno, ao território mais próximo, o que acontece nesta dimensão entre vida e arte? Imersos em lives, congressos, festivais, eventos e partilhas, entre o público e o privado, a partir da intensa presença do recurso audiovisual em rede nas práticas de vida cotidiana, nos questionamos: como o audiovisual tem funcionado como ponto de encontros e possibilidades - encruzilhada - (RUFINO, 2018; SIMAS e RUFINO, 2019) para abrir caminhos na busca por reestabelecer o fluxo da experiência estética em tempos de pandemia? Que implicações estéticas e políticas podemos vislumbrar a partir deste fenômeno? Propomos aqui o exercício de fabulação e reflexão a partir de nossa constelação sob o signo da morada, constituída por obras que têm o audiovisual como recurso estético/político de relação e encruzilhada entre as artes e a vida partilhada em família, entre amigos, em comunidade.

Nosso interesse de pesquisa brota da experiência de produtoras/coletivos de cinema ligadas a territórios periféricos e que filmavam em família, em casa, entre amigos, em comunidade, nos lugares de afeto, escolhidos para viver/filmar, em propostas antes mesmo da eclosão da pandemia, entre as quais No Coração do Mundo (Maurílio Martins e Gabriel Martins, 2019) e Até o fim (Ary Rosa e Glenda Nicácio, 2020), por exemplo, respectivamente da Filmes de Plástico e da Rosza Filmes. Os dois exemplos são ficções com perspectivas comunitárias que permitem vislumbrar gestos de partilha do sensível (RANCIÈRE, 2009) ao mesmo tempo singulares e em diálogo, na trajetória destes dois coletivos/produtoras, que ganharam reconhecimento nacional e internacional filmando suas relações de pertencimento.

Realizadores ligados a esses grupos seguiram produzindo em tempos de pandemia: Gabriel Martins, com Movimento (2020), Incluindo Deus (2020), de Maurílio Martins, e Pai (2020), de André Novais Oliveira, ambos ligados à Filmes de Plástico; Ary Rosa e Glenda Nicácio, da Rosza Filmes, que filmaram durante a 
quarentena uma família que estava em isolamento na mesma casa; Voltei!, lançado em festivais em 2021, que, por sua vez, retoma presenças de Até o fim (2020), filmado antes da pandemia, mas realizado praticamente em uma locação. Diversos outros realizadores também lançaram obras inquietantes à luz da intimidade familiar/comunitária em festivais e mostras desde o ano de 2020.

Esses audiovisuais são tomados como encruzilhada no diálogo não apenas entre o público e privado, potência e invenção no comum, mas também com outras artes que se transformaram durante a pandemia. É o caso da música, com as Jovens Lives de Domingo realizadas desde abril de 2020 até os dias atuais por Teresa Cristina e D. Hilda, sua mãe, no canal do YouTube da sambista; a peça teatral/audiovisual Jacksons do Pandeiro que estreou em 10 de outubro de 2020 no YouTube, além da reencenação audiovisual do espetáculo musical Auê em julho/2021, ambos realizados pela Barca dos Corações Partidos, ou ainda as lives de samba de roda no Facebook realizadas pela Casa de Samba Dona Dalva Damiana, no segundo semestre de 2020, especialmente as de setembro de 2020, que precederam o aniversário da doutora do samba, e o dia dos santos Cosme e Damião. Outra experiência, em 2021, foi a peça audiovisual Até o fim, também no Youtube, gerando imagens distintas, inclusive, do filme homônimo de Ary Rosa e Glenda Nicácio (2020). Também temos a peça audiovisual Encruzilhada (2021), da Cia La Bagaça, no Youtube da Casa Preta Espaço de Cultura. Há, ainda, a série de vídeos de humor Sinta-se em casa, de Marcelo Adnet. Em suas performances caseiras, o humorista encena situações do cotidiano e sátiras de personagens públicos. Também disponível na Globoplay, a série Amor e Sorte foi filmada na casa dos atores, com participação dos familiares/casais confinados, com equipes reduzidas e/ou remotas.

Pinçadas essas experiências, compreendemos a recorrência do audiovisual como possibilidade de abrir caminhos para o compartilhamento de espaços e presenças, da arte e da vida. Diante deste firmamento infinito de possibilidades, como gesto inicial, buscamos construir uma constelação do audiovisual em intimidade comunitária, em morada, a partir do cinema e das lives, e refletir sobre ela, contemplando-a. Trata-se de um movimento metodológico inspirado na constelação benjaminiana e também na constelação fílmica (SOUTO, 2019), em que se estabelecem relações entre diversos filmes, fazendo emergir desta comparação aspectos de proximidade, simpatia, divergências e/ou rupturas, por exemplo, que permitem a produção de outras imagens e imaginários, de continuidade ou de interrupção - seja 
dos corpos da cena, sob perspectivas estéticas, forma audiovisual, encenação, seja dos corpos em cena, performances engajadas.

Desenhamos a constelação da morada a partir das experiências selecionadas. Essas experiências transcendem binarismos, assim como a imagem vai além da evocação da noção de aparição/concepção de um espaço físico (a casa, o apartamento, o domicilio privado). A constelação da morada nos indica corpos, linguagens e práticas partilhadas que remetem à abertura ao comunitário - como nas práticas de Tia Ciata e das tias baianas no Rio de Janeiro (SIMAS; RUFINO, 2019) ou de experiências amefricanas e ameríndias. Ainda que em tempos pandêmicos, a nossa constelação da morada borra o binarismo próprio/comum, público/privado, corpos/planos e incorpora, ao mesmo tempo, os territórios partilhados, os corpos e o próprio audiovisual, operando entre planos do visível e do invisível.

\section{Fabulações sob o signo da morada}

\section{Figura 1 - Constelação do audiovisual como encruzilhada comunitária}

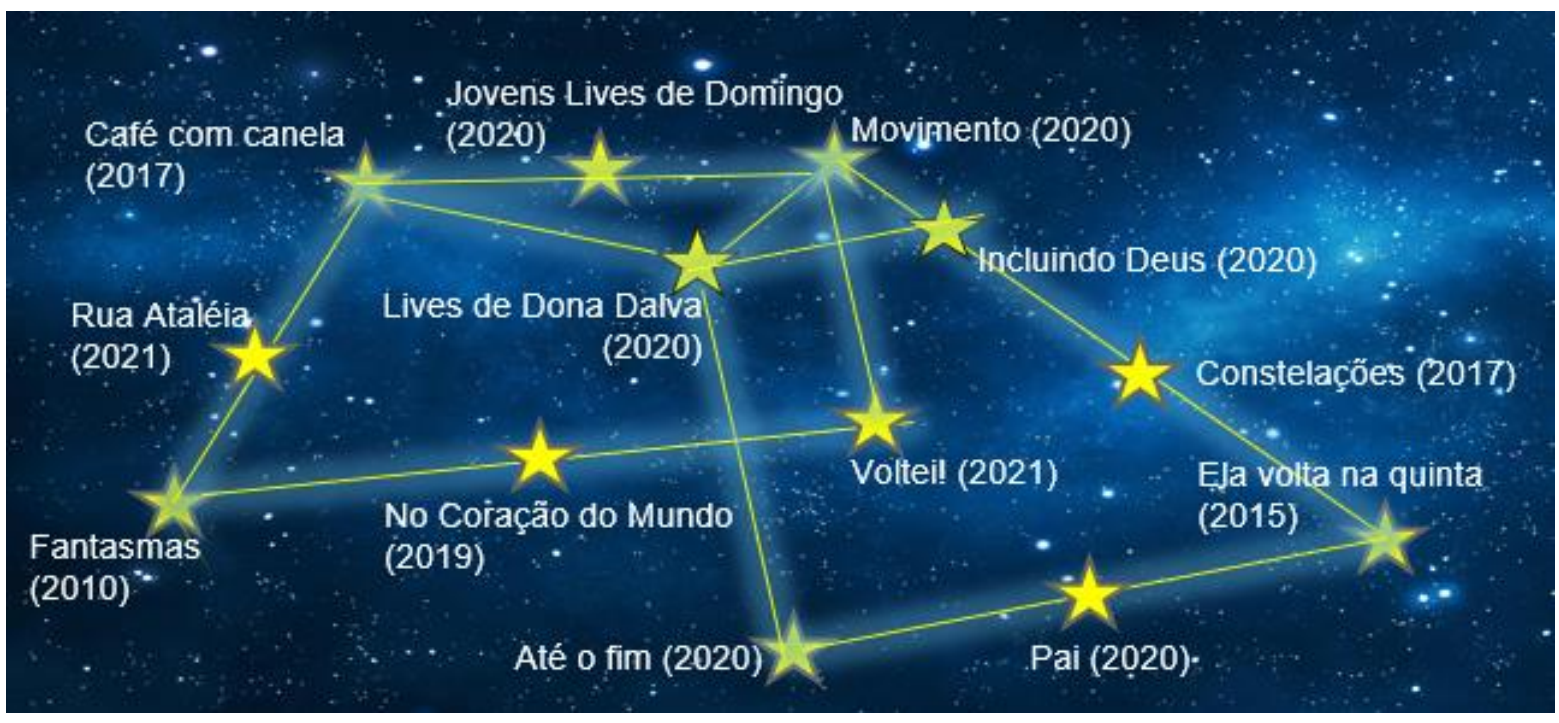

Fonte: acervo dos autores4.

Partimos de um ponto de chegada. Chegamos a outras partidas. Partir/chegar

\footnotetext{
4 O template usado para abarcar a nossa constelação audiovisual foi feito com base na apresentação de uma constelação fílmica construída e apresentada no Congresso Internacional de Culturas, no trabalho "Mergulhar e respirar: cinemas do entrelugar em Ceilândia, Contagem, Recôncavo e a experiência indivisível", de autoria de Angelita Bogado, Scheilla Franca de Souza, Francisco Alves Junior, Ana Luisa de Castro Coimbra e Lina Cirino, integrantes do GEEECA/UFRB, grupo a quem agradecemos especialmente pelas contribuições, diálogos e parceiras.
} 
são vistos também além dos binarismos, assim como fazem as propostas em cena, que encontram na morada (espaço de viver, partilhado) também espaço de propor experiências estéticas, pulsar imagens que transcendem o dentro/fora, o próprio/comum, e deixam marcas nos corpos audiovisuais, pelas performances e encenações. Essa é uma imagem construída, fabulada, a partir de imagens que pulsam da experiência destes corpos audiovisuais, revelando espaços de viver/filmar, como morada de muitas experiências estéticas que rompem padrões eurocentrados, coloniais. É um formato que convocamos o leitor a retomar, ao longo do texto. Ir-virvoltar-ir são movimentos de olhar, partidas/chegadas, que unem as propostas que compõem a constelação da morada. O formato fabulado por nós, ao contemplar a miríade estelar do firmamento de produções artísticas que realizam suas experiências pelo audiovisual como forma de partilha da experiência estética vivida/imaginada, é o de uma espécie de abrigo sem portas fechadas. Nos remetemos assim, livremente, a uma poética das moradas originárias, anteriores àquelas implantadas no Brasil colonial - com as transgressões presentes nas pedrinhas miudinhas, do comum amefricano e ameríndio, que, mesmo sofrendo processos de apagamento, seguem resistindo na forma e força do cotidiano periférico e comunitário (SIMAS; RUFINO, 2019). Uma casa aberta em frente e fundo, sem cômodos separados e cujos limites entre as ligações estelares vão além dos corpos interligados. Território de partilha faz ecoar possibilidades de cruzamento do audiovisual com artes e proposições estéticas, com a vida, a comunidade, o público/privado. Não há início delimitado, nem fim: todos os pontos apresentam conexões estéticas/políticas de mão dupla.

Em nosso corpus, fazemos saltos temporais retroagindo dos dias atuais até o início da década de 2010, explorando experiências realizadas no Brasil. Aqui, mais diretamente, nossa ideia é de seguir a partir do ponto constelar onde nasce o desejo desta pesquisa encruzada: as Jovens Lives de Domingo, de Teresa Cristina e sua mãe, Dona Hilda. Fazemos um diálogo direto com o encantado filme Pai (3min, 2020) de André Novais Oliveira, atravessado por outras proposições, como Fantasmas (2010), também de André Novais Oliveira. A partir desses três pontos dentro da nossa miríada, trazidos ao primeiro plano neste trabalho, damos a ver interrelações entre os demais corpos celestes desta constelação como Ela volta na quinta (2015), Café com canela (2017) e as lives de dona Dalva (2020), por exemplo.

Em 2020, através de suas lives nas plataformas digitais, a sambista Teresa Cristina ganhou ainda mais notoriedade, para além do mundo do samba, onde já era 
muito aclamada e reconhecida. Desde abril de 2020, em seu canal do YouTube, ela vem fazendo uma live, que, do ponto de vista das narrativas familiares, íntimas e em comunidade, chama a atenção: a live semanal, com aproximadamente uma hora de duração, intitulada Jovens Lives de Domingo. Neste evento, o repertório é o de sua mãe, que canta as músicas que sempre gostou de cantar em casa, na intimidade, agora compartilhadas com os espectadores, seguidores da TT, os Cristiners, como são chamados. O repertório de Dona Hilda extrapola o do samba, universo pelo qual Teresa é mais conhecida do público. São canções populares brasileiras, boleros, valsas, músicas românticas, em geral, de artistas como Roberto Carlos, Fábio Jr., Altemar Dutra, Nelson Gonçalves, Roupa Nova, Vanusa, Carlos Galhardo.

Temos, assim como nas lives de Dona Dalva, a presença do plano fixo, na horizontal, como sustentação do corpo da cena, das perspectivas de encenação desta experiência de viver/filmar. O plano fixo já tinha sido morada de experiências em família/comunidade, sobretudo no cinema periférico, em coletivos, no cenário recente. Há uma performance de continuidade (CARDOSO FILHO; GUTMANN, 2019), entre os corpos em cena e da cena (BOGADO; ALVES JUNIOR; DE SOUZA, 2020), mas com diálogo com outra corporalidade audiovisual: o cinema. Teresa poucas vezes aparece inteiramente em campo, deixando, na maior parte do tempo, ver apenas parte de si. Tendo sua mãe ao seu lado - é a mãe quem está mais ao centro do quadro -, não é incomum vermos, na maior parte do tempo, apenas metade do corpo de Teresa, ou parte de seu braço (onde percebemos a tatuagem de um espelho de Oxum, orixá de culto da cantora) ou metade do rosto, para evidenciar a companhia e a partilha da experiência com a mãe, sem deixar de dar a ela, mãe negra já idosa, o protagonismo.

Normalmente sua mãe canta e a filha organiza seu repertório, lê comentários, mostra a reação do público marcada por emojis (performance espectatorial que normalmente arranca um sorriso encantado e encabulado de Dona Hilda) e pedidos de música. Entre canções, há a pausa para buscar o remédio, relembrar a letra, beber água, para as pequenas discussões próprias dos afetos familiares, as lembranças, as histórias de família, recadinhos e carinho para a vizinhança, preces. A live sempre tem terminado com sua mãe performando a Ave Maria, sem letra, apenas com a voz fazendo o som da melodia, e demarcando o caráter ritualístico da proposta. Dizemos assim, 'tem acontecido', compreendendo que essas corporalidades da cena e das performances apresentam muita abertura para irromper o inesperado, gerando alterações de padrões dentro dessas gramáticas. 
Esta seria uma das características dessas "corporalidades criadas pelo coronavirus", segundo Paula Coruja, como comenta a autora ao analisar produções de Youtubers (CORUJA, 2020). O mesmo vale para os cenários e ambientes em cena. A seguir, vamos colocar certo padrão que pudemos perceber, embora, em casos pontuais, já tenha havido alterações (gravações fora do quarto onde normalmente acontecem as lives, elementos cênicos alterados). Os elementos em cena mostram afetos, objetos de culto (como uma imagem da divindade das águas doces nas religiões de matriz africana) e engajamentos políticos partilhados em um espaço de intimidade, um quarto, com uma janela aberta para a rua, onde pode caber o mundo (temos em cena muitas vezes no canto oposto à janela do quarto, um globo terrestre). Perto da porta (espaço de trânsito e encontro com outros espaços da casa) vemos em destaque a placa da rua Marielle Franco.

\section{Figura 2 - Prints da transmissão de 20/12/2020 de Jovens Lives de Domingo, especial Roberto Carlos}

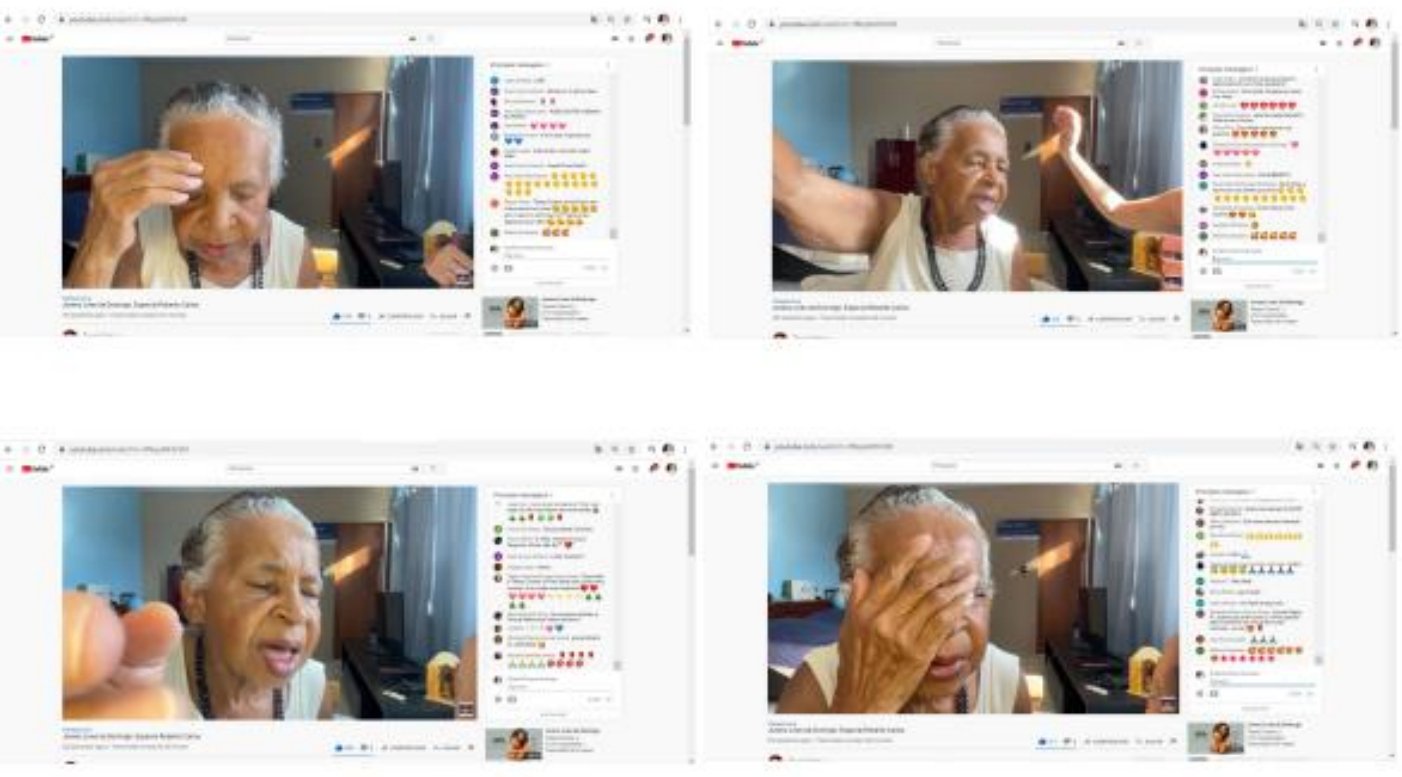

Fonte: Canal do Youtube da cantora Teresa Cristina.

O afeto se manifesta também via chat ao vivo, onde as pessoas comentam com emojis, agradecem, pedem músicas, compartilham histórias semelhantes de mãe e filha. Muitas vezes, identificam-se com o espaço criado, pela relação e as imagens que dela emergem, transbordam de lá para cá e vice-versa, já que a reação e o posicionamento do público espectador também engajam as protagonistas da live em 
suas performances. No dia 20 de dezembro de 2020, tendo em vista que não houve um especial ao vivo inédito de Roberto Carlos, de quem a mãe é fã, mãe e filha fizeram um especial de Natal com músicas de Roberto Carlos, como proposta pessoal de encontro e tentativa de restabelecer esse fluxo de experiência (DEWEY, 2010), que havia sido interrompida. Palmas, coreografias com os braços e gestos com as mãos fazendo a "orquestra vocal" muitas vezes ocorrem marcando a parceria de mãe e filha, transbordando o plano e lembrando que há limitações dentro das possibilidades de apreensão daquela experiência, embora isso não a faça menos potente, apenas marca o momento em que vivemos. As músicas são todas cantadas à capela, e, mesmo em suas partes orquestradas, muitos sons são imitados pela performance vocal, recurso que Teresa, assim como Dona Hilda, também usa em suas lives individuais no Instagram, que podemos entender como uma performance que marca a relação entre mãe e filha, e que talvez possamos fabular como tendo sido apreendida, herdada, do canto caseiro materno.

Na live de Teresa e sua mãe no YouTube, a posição da câmera é deitada, gerando um plano horizontal, que centraliza a mãe, dá a ver a filha, e abre o campo para abarcar o espaço íntimo, frequentemente um quarto, mas também, quando necessário, em outros ambientes. É uma imagem que abarca a centralidade do diálogo, da relação íntima que se dá em casa, e que, assim, ajuda a ampliar o espectro da representação. Ao horizontalizar a captação da imagem, elas remetem não diretamente às imagens de celular, mas ao formato da tela dos vídeos do Youtube, desejando ocupar todo o espaço disponível, e ainda - por que não? -, possibilitar o salto para o olhar cinematográfico. É uma forma de potencializar a encruzilhada, além de ser um gesto que permite melhor captação, que a relação ocupe aquele território audiovisual e que suas performances sejam apreendidas, assim como o espaço e os elementos de cena.

Em Pai, de André Novais Oliveira, da Filmes de Plástico, filme realizado quando do retorno do filho à casa do pai, após muito tempo, há o recurso da fotografia da casa, que inicia o filme com imagens estáticas horizontais, como aliás começa Ela volta na quinta (2015), por exemplo, com imagens fotográficas de família. Aqui, temos a casa. No entanto, ao longo de todo o filme há imagens feitas em formato horizontal e vertical, escolha estética que revela a relação dialógica do cinema com as imagens digitais feitas por celular. Além destas, marcam esta encruzilhada audiovisual uma gama de fotografias e arquivos de tempos outros, indefinidos, que, podemos fabular, se tem acesso quando se está em casa e quando alguém lhe confere acesso àquelas imagens. 
São imagens que marcam a partilha comunitária, familiar, na feitura do filme.

\section{Figura 3 - Heterogeneidade de formatos e temporalidades em Pai}
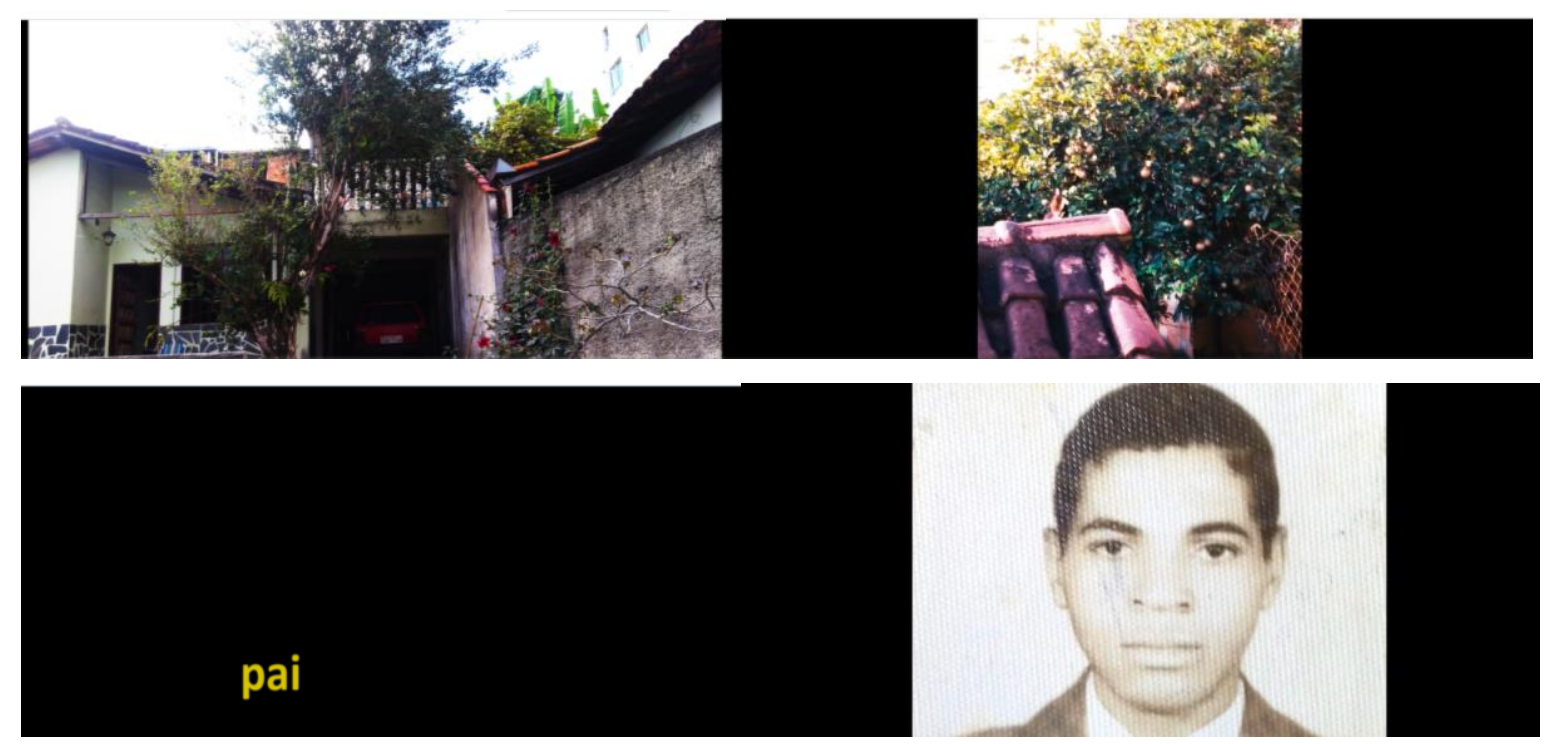

Fonte: Filme Pai, de André Novais Oliveira (2020).

Não há a performance vocal de André narrando as imagens em tela. A escolha para contagem dessa experiência estética se dá a partir das legendas, do texto escrito. Texto este que revela imagens de André e de seu pai, Norberto, em casa durante a pandemia. Imagens irrompem pelo afeto, pela intimidade, fissurando o espaço privado e ganhando dimensões políticas. Ao propor visibilidades outras para além do hegemônico, as imagens funcionam sob outras lógicas de economia, ou seja, de gerenciamento entre o visível e invisível (MONDZAIN, 2013). Imagens são paridas sob outras lógicas de visibilidade da figura paterna comum, ao darem corpo à experiência de partilha entre pai e filho.

O título do filme é proposto ao espectador em plano preto com letra minúscula. A imagem do pai, então, emerge da tela preta, do invisível, mas não ausente de imagem, evocando a relação próprio/comum. O pai vem à luz em sua dimensão mais terrena, além do tom maiúsculo que marca a escrita cristã de nossa cultura. A imagem de pai proposta por André, seu filho, é de um pai não idealizado, um pai concreto, um pai substantivo comum, um pai em luto, com acertos, ausências, presenças e com o desejo de partilhar com o filho, de ensinar como forma de experiência de partilha e fortalecimento dos vínculos, ainda que não o saiba fazê-lo com excelência (é o caso da aula de violão durante a pandemia). Música, cinema e vida cotidiana, pela encruzilhada 
audiovisual, propõem imagens que emergem da relação, do "entre" pai e filho/ mãe e filha. A partir das frestas (RUFINO, 2018) dessa experiência possível, saltam imagens nas quais ecoam muitos pais, um homem negro de cabelos já enbranquecidos que nem sempre tem receitas ou modelos de como ser pai a seguir, para reencenar, como revela o texto escrito. Uma imagem muito comum entre nós, trazida de forma muito própria pelo cinema de André, que surge das performances e encenações, entre estas e além delas, no olhar espectatorial, à luz desta perspectiva afetiva.

Temos em diálogo e por meio da relação a emergência de imagens de imagens, perspectivas que nosso olhar constrói a partir das imagens propostas (MONDZAIN, 2013) de mãe e pai, de filha e filho, de relação a partir da subjetividade e presença de mulheres e homens negros. Mães e pais em processo de envelhecimento, em espaços e papéis, cenas e performances, que brotam com a força da intimidade, por esse audiovisual que opera nas frestas e que gera rupturas pela aparição dessas presenças, se pensarmos as perspectivas de visibilidades mais hegemônicas no audiovisual. Não foram poucas as vezes em que esses corpos reivindicaram lugares no audiovisual. Nas margens, nas encruzilhadas audiovisuais (RUFINO, 2018; SIMAS; RUFINO, 2019), essas imagens surgem distantes dos modelos hegemônicos também na forma de incorporação de outras gramáticas, como as dos vídeos feitos por celular e postados nas redes, trazendo esses sujeitos e as formas de narrá-los em performances íntimas, afetivas, partilhadas e, por isso mesmo, políticas, para o centro da experiência. Encantamento do comum, reposicionamento de corpos. Imagem e visibilidade são perspectivas distintas, trazidas à tona e problematizadas aqui à luz do pensamento de Marie-José Mondzain, sobretudo. O reposicionamento dos corpos dá a ver essas dinâmicas entre o visível e o invisível de uma imagem e suas implicações políticas.

Esssas mudanças não ocorreram somente no período pandêmico: Café com Canela (2017) traz o protagonismo negro feminino, e com ele também a presença de Dona Dalva, o samba e as tradições de matriz africana de Cachoeira-BA, em um filme oferecido à Oxum. Ao lado da querida e saudosa Dona Zezé, sua esposa, Norberto atuou em Ela volta na quinta (2015), com seus filhos e amigos, e sua casa foi ainda o espaço onde aconteceram as filmagens de Fantasmas (2010), filme que deu projeção à Filmes de Plástico, assim como o quintal deu título a um filme homônimo realizado pelo filho. Não é à toa que se filma em comunidade. Não fosse assim, mesmo sem a pandemia, seria muito mais difícil que essas imagens ganhassem corpo. O comunitário é fresta. O plano fixo é encantado e evocado em nossa constelação desde Fantasmas (2010), 
uma vez que pode ser lido como possibilidade de incorporação do comum, do partilhado, um recurso com potência de propor outras relações de visibilidades/invisibilidades. Nas Jovens Lives de Domingo e em outros audiovisuais da nossa constelação, o plano fixo faz com que o corpo de cena incorpore, ainda que por alguns instantes, o inapreensível, o que está entre, em todo lugar e em lugar específico algum, na sua economia imagética. Assim como vimos a morada como palco, espaço que compõe a encenação para a aparição dessas performances, ela é também imagem entre, que guarda/revela sentidos além do visível/invisível, das frestas da casa que vemos em cena, entre casa/rua, público/privado, próprio/comum.

Figura 4 - O plano fixo como forma econômica de gestão da imagem

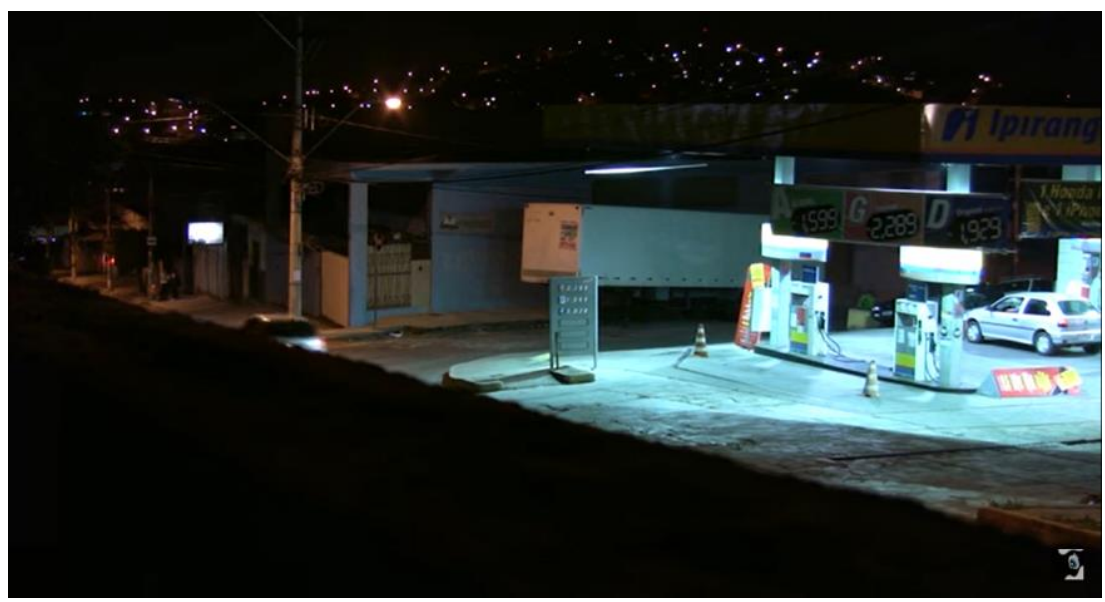

Fonte: Filme Fantasmas (André Novais Oliveira, 2010), canal da Filmes de Plástico no Youtube.

Aqui, entre esses pontos e neles mesmos, apresentam-se potências de diálogo acerca da aparição da experiência familiar/comunitária que tem o audiovisual como encruzilhada da experiência estética, operando nas frestas e fortalecendo práticas comunitárias da nossa matriz negra/indígena, que foi enfraquecida pela herança colonial que nos habita. Na nossa constelação, essa experiência comunitária é agenciada de modo a valorizar formas de realização e autoria que, como sustenta André Brasil (2021) ao analisar o cinema feito em comunidades indígenas, transfiguram a força dos comuns, a diversidade de tessituras, estéticas, encenações, de performances que incorporam a força dos dendezeiros (SIMAS; RUFINO, 2019). 


\section{Figura 5 - O plano fixo, as máscaras pandêmicas: relação com o digital em cena} e no corpo da cena

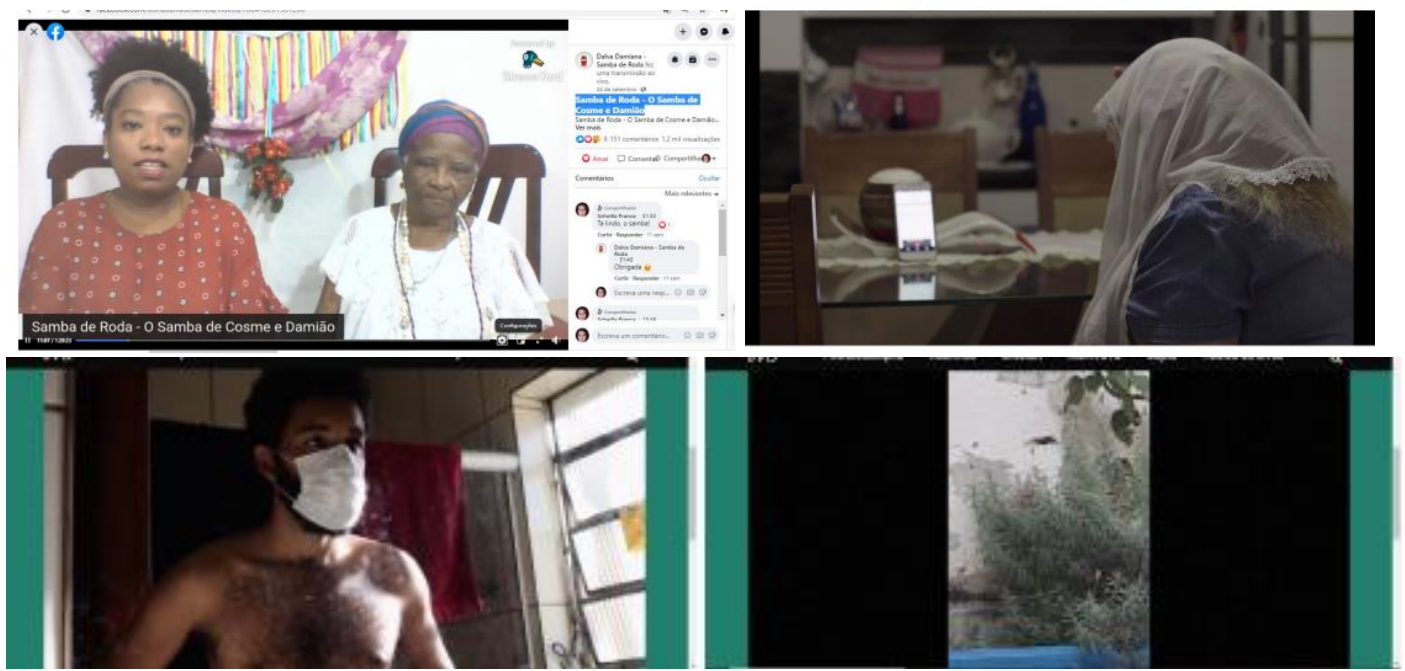

Fontes: Lives do Samba de Dona Dalva (24 de setembro de 2020) no Facebook, Incluindo Deus, de Maurílio Martins, e as duas imagens de Movimento, de Gabriel Martins, ambos filmes de 2020.

Retomamos e friccionamos imagens, constelando-as (SOUTO, 2019), revelando algumas faces do invisível que trazem essa configuração constelar da morada e deixam marcas nos corpos audiovisuais. Aqui já conseguimos observar, por meio das experiências abordadas de forma mais direta, a presença do plano fixo, da hetorogeneidade das imagens, dos corpos em cena e da cena, em seus reposicionamentos e partilhas do sensível (RANCIÈRE, 2009). Como um todo constelar, salta o fazer comunitário, familiar. A partir das Jovens Lives - e sua câmera fixa horizontal -, podemos ter um diálogo com a câmera fixa horizontal em Fantasmas (2010), ou ainda aquela que está posicionada em determinado ponto específico do espaço em Movimento (2020) para captar o amor familiar a partir da gestualidade e dos corpos dos três membros da família, e cuja virada para o plano vertical pode revelar, naquele contexto, possibilidade de captar o imponderável e encantado voo cotidiano mesmo em isolamento, além de cruzo com outras formas do audiovisual.

O plano vertical pode ser para a experiência de Pai, uma das formas de demarcar o diálogo com o contexto da pandemia. Afinal, a imagem vertical remete à imagem de celular, que vai mediar nosso contato com o mundo em isolamento, assim como a presença da máscara, do celular e a troca de áudios de WhatsApp em Movimento (2020) ou a performance e o culto religioso da mãe via celular registrada pelo filho Maurílio em Incluindo Deus (2020) e a máscara no início de Voltei! (2021), mesmo no 
futuro, diegeticamente. A repetição da presença dos corpos da cena, em papeis variados, ocorrem, podemos pensar, pela liberdade de se estar em casa, em família como em Pai (2020) e Ela volta na quinta (2015) e ainda em outros filmes da Filmes de Plástico, como Mundo Incrível Remix (2014), Contagem (2013), Constelações (2017) e No Coração do Mundo (2019). Essa forma de repetição, com novas incorporações, é um recurso perceptível ainda em Café com Canela (2017), Até o fim (2020) e Voltei! (2021), da Rosza Filmes. Fazem ver os nós, os enlaces, as relações, as permanências e as transformações.

Rua Ataléia (2021), também de André Novais Oliveira, da Filmes de Plástico, evoca no título o espaço público, embora se construa sobre o íntimo partilhado, à meia luz, a maior parte do tempo em casa, à luz da memória (um olhar de 2021 sobre imagens captadas em 2011) evidenciando a relação família/comunidade e casa/rua, superando dicotomias, como marca também a placa Rua Marielle Franco no quarto das Jovens Lives de Domingo.

No audiovisual comunitário como encruzilhada, experiência estética possível e potente, o cinema não é só cinema mais, nem a live de música exclusivamente live de música. São cada uma dessas coisas, e ainda outra: encruzilhada que incorpora formas e conecta presente-passado-futuro com outras imagens possíveis de nós.

\section{As potências do audiovisual como encruzilhada}

Trazemos a constelação da morada como oferenda, enlace de experiências estéticas e teóricas, para refletir sobre vida/arte de forma familiar e comunitária. Sigamos com essas imagens em mente. Mergulhemos um pouco mais no céu sob nossos pés. O conceito de encruzilhada que trazemos para pensar as experiências, já brevemente apresentadas, constitui o audiovisual como possibilidade de existência e partilha. Observamos nessas experiências, tendo Exu como símbolo de ambivalência e transgressão, gestos que dão uma rasteira - como dizem as práticas da malandragem - na escassez de compartilhamento de vida e arte, fazendo brotar pelo audiovisual outras gramáticas e corpos como possibilidade de experiência, de "estar junto", afinal, "a encruzilhada em que vivemos lança a nós uma questão: como combater o desperdício, a escassez, o desencanto propagado por um regime contrário à vida?” (RUFINO, 2018, p. 71).

O audiovisual "acende a vela e vela a vida" (RUFINO, 2018, p. 74) para 
seguirmos essa pergunta como rastro que salta do agora para o muito antes, e viceversa, para um Brasil colonial que não cessa de cessar formas de vida, há séculos. Como encruzilhada, o audiovisual é "ambivalente, não define lado, é o palco de todos os tempos e possibilidades" (RUFINO, 2018 p. 37), operando na fresta, na escrita em trânsito, no entre, encantado por Exu, olhando para o segredo das pedras miúdas, dos frutos do dendezeiro, do cotidiano simples e compartilhado afetivamente nas relações. Assim, as experiências elencadas, trazidas para a constelação, operam na rasura, na emergência de outras gramáticas, formas e imagens contra o extermínio da pluralidade, vencendo dicotomias, afinal "Exu ao colidir com algo se transforma em um terceiro elemento, não mais o primeiro, nem o segundo, mas um 'entre"' (RUFINO, 2018, p. 53). Acreditamos ser este ponto riscado na experiência, nas performances e incorporações dialógicas, uma primeira implicação estética e política observada. Tratamos de algo que, como vimos, não se iniciou com a pandemia, mas foi fortalecido por ela, os elos da experiência de intimidade familiar/comunitária, cujas formas de apreensão - em sua economia e gramática - retomam tradições e o atual, e ajudam a fabular o mundo pós-pandemia e suas produções midiáticas e artísticas.

O audiovisual, em cruzo com outras artes e formas de vida partilhadas pelo afeto, potencializa encontros, existências, caminhos, experiências, criação. O hibridismo está fortemente presente no gesto encruzado das experiências, entre a live de música e o cinema, entre o cinema e as imagens de celular compartilhadas nos ambientes virtuais, produzidas pelos aparatos digitais que marcam as obras. Ou seja, a heterogeneidade é um legado possível, como vimos nas imagens consteladas.

A encruzilhada é o principal conceito assente nas potências do orixá Exu, que transgride os limites de um mundo balizado em dicotomias. A tara por uma composição binária, que ordena toda e qualquer forma de existência, não dá conta da problemática dos seres paridos no entre. A existência pendular, a condição vacilante do ser é, a princípio, o efeito daquilo que se expressa a partir do fenômeno do cruzo. [...] A potência da encruzilhada é o que chamo de cruzo, que é o movimento enquanto sendo o próprio Exu. O cruzo é o devir, o movimento inacabado, saliente, não ordenado e inapreensível. O cruzo versa-se como atravessamento, rasura, cisura, contaminação, catalisação, bricolagem - efeitos exusíacos em suas faces de Elegbara e Enugbarijó. O cruzo é a rigor uma perspectiva que mira e pratica a transgressão e não a subversão, ele opera sem a pretensão de exterminar o outro com que se joga, mas de engoli-lo, atravessá-lo, adicioná-lo como acúmulo de força vital (RUFINO, 2018, p. 13-15).

A encruzilhada, enquanto forma de existência e expressão, faz sobreviver, em 
tempos de pandemia, a experiência de ancestralidade, que se insinua como presença no mundo em devir. Isto se dá, segundo Simas e Rufino (2019), em função da particularida do Novo Mundo (uma encruzilhada) a partir da diáspora africana, do encontro com os povos originários e dos colonizadores europeus. A tragédia colonial é ressignificada pelas subjetividades como potência e invenção (RUFINO, 2018). O corpo na encruzilhada audiovisual é possibilidade - a partir do cruzo, entre resiliência e transgressão, da retomada do fluxo da experiência estética e da vida, "para fazer outros caminhos - essa é a potência da transformação assente nas encruzilhadas” (RUFINO, 2018, p. 8).

Enquanto proposição estética há um legado que se configura a partir do reposicionamento destes corpos em cena e da cena, reflexo das lutas e esforços para o reconhecimento de outras epistemes, cosmogonias, perspectivas, sobretudo ameríndias e amefricanas, assim como o trabalho de diversos coletivos, realizadores, artistas e ativistas - das artes em geral, mas aqui especificamente pensamos no audiovisual, no cinema e no audiovisual - periféricos, que trazem o comunitário (periférico regional, urbano, negros, quilombolas, indígenas), as relações entre os sujeitos, seus afetos, a relação com o território, com o não humano, com o invisível.

Um outro vislumbre de implicações estéticas e políticas que lampeja aqui é a urgência de viver outras experiências no audiovisual, na mídia, nas artes - na vida. $\mathrm{O}$ mundo pandêmico evidenciou muitos aspectos nocivos das nossas relações com objetos, ambientes, sujeitos, de nossas relações de visibilidade e invisibilidade. Há muito tempo nossa relação com a imagem, como dispositivo de poder, é campo de disputa, com forte apelo binarista e de exclusão, como forma de dominação das formas de ver e fazer ver, como pontua Marie-José Mondzain (2013), ao retomar o cenário e a crise bizantina para, em seu método histórico, evidenciar as patologias da imagem e suas raízes.

Durante a pandemia, seguimos lidando com essas questões, mas em diversas experiências vimos retomados, reiterados e também reformulados outros gestos e formas de vida e imaginário, sobretudo a partir do comunitário/familiar. Tais gestualidades nos permitiram experienciar a emergência de corpos audiovisuais, com a ainda mais forte presença das redes digitais. Entretanto, em seu necessário uso de telas, essas experiências pandêmicas também se desgastam e apontam para as possíveis precariedades e insuficiências.

Isso aponta para a urgência em reconhecer potencialidades e limites desses 
corpos eletrônicos e a dinâmica de vida que este estar no mundo mediado pelas telas, exclusivamente, nos trás. Tateando ainda no escuro do aqui-agora-ontem alumiados pela constelação encruzilhada da morada, pensamos ser necessário fabular outros modos de estar no mundo - incorporando os aprendizados do desejo do Outro no mundo pandêmico e antes dele - para parir gestos de continuidade e ruptura. Inclusive no fazer audiovisual, nas corporalidades em cena e da cena.

Observamos que, assim como na encruzilhada, as constelações, no caso de Benjamin, também permitem estes saltos no tempo. Georg Otte e Miriam Lídia Volpe (2000), ao olhar para o pensamento constelar em Walter Benjamin, pontuam:

\begin{abstract}
Antes que o ritmo agitado e a luz artificial da vida moderna atrapalhassem a observação demorada e detalhada do espaço, percebeu-se uma regularidade no movimento cíclico de um grande número das estrelas visíveis que rotavam, em agrupações permanentes, formando certos padrões. Dessa regularidade dos corpos celestes, o homem criou um sistema que o ajudou a pôr ordem na compreensão do mundo em que devia sobreviver, principalmente no que concerne aos conceitos de tempo e de espaço. A partir daí, ele associou determinados tempos e movimentos cósmicos com a época dos plantios e das colheitas, que evoluiu na criação do calendário das sociedades mais complexas e encontrou, na constância da forma e movimento desses grupos de astros, um sentido de direção e de orientação para as viagens de expansão terrestres e marítimas. Os pontos mais brilhantes desses grupos de estrelas, que se destacavam ao olhar do observador, estimularam a imaginação do homem a traçar linhas que os interligassem formando figuras e narrativas significativas segundo as épocas e os lugares. [...] A metáfora da constelação certamente foi uma das inspirações mais importantes de Walter Benjamin. (OTTE E VOLPE, 2000 p. 36).
\end{abstract}

A metáfora das constelações em Benjamin é uma forma de conseguir perceber o que o "progresso" e suas alterações e impactos na capacidade de narrar nos impedem de perceber. Nas temporalidades das constelações, há certa regularidade na circularidade e o tempo/espaço pode ser observado de forma mais alargada, ampliada, panorâmica, para permitir os saltos que interligam os pontos estelares. Embora os fluxos entre os pontos possam se comportar no ir-e-vir - fora da linearidade - das imagens que saltam pelo olhar, os movimentos dos eixos constelares necessitam de certa regularidade e de alguma distância - embora haja o lampejo de um corpo em outro - em uma temporalidade histórica sem limites, mas sempre mais ampla.

A encruzilhada de Exu bebe e dialoga com os saltos e as temporalidades constelares benjaminianas, em aproximações - a não linearidade temporal, sobretudo 
- porém com ações que talvez priorizem uma temporalidade mais breve, embora não se exclua a retomada de gestos, ou ainda, a reiteração de comportamentos hoje, de movimentos e imagens ancestrais, de tempos apagados pela história. O corpo audiovisual tem potência de transitar no diálogo dos cruzos de maneira mais manifesta, pela incorporação mais direta das formas de expressão. Há, pois, diálogos fortes entre as constelações e encruzilhadas.

Através de Exu, da experiência da linguagem que não exclui, mas incorpora, invocamos o pensamento benjaminiano, a quem Simas e Rufino chamam de "caboclo alemão":

Orunmilá e Exu são aqueles que enxergam, conhecem, acessam e caminham em todos os tempos/espaços. Exatamente por isso, Orunmilá, dotado de sabedoria infinita, é aquele que nos aponta as formas de potencializar os caminhos. Exu, por ser a própria dimensão de todo e qualquer movimento e ação criativa, é a força que opera nas ações que buscam a transformação. Assim, Orunmilá e Exu operam de maneira integrada, cruzando os diferentes campos do conhecimento, atuando na capacidade de interagir com os mesmos e gerando novos efeitos. Dessa maneira, eles fundam e estabelecem todo e qualquer princípio de comunicação, por isso são as potências ligadas à diversidade de formas possíveis e suas escritas. Rumando a prosa, atemo-nos ao que nos diz Walter Benjamin, caboclo alemão, em suas teses Sobre o Conceito da História. (SIMAS; RUFINO, 2019, p. 14).

Se para os autores Simas e Rufino, “o Brasil, há de se dizer, é resultado do extermínio secular das experiências comunitárias, negras, indígenas e das populações empobrecidas" (2019 p. 22) não é à toa a ação de filmar comunitariamente, em coletividade, encantando as performances e rituais do cotidiano e extraindo das relações partilhadas gramáticas e experiências de potência de vida, gesto/encruzilhada que faz ver imagens que estabelecem e reivindicam outras partilhas do sensível (RANCIÈRE, 2009), imagens dissensuais de Brasis: eis o emaranhado ético, estético e político que podemos ver através das imagens dos praticantes das margens. Destacamos que as relações entre os corpos em cena e os corpos da cena no audiovisual contemporâneo mobilizam o diálogo entre performance e encenação, estreitando relações entre o vivido/imaginado (BRASIL, 2014), entre estética e política, fazendo ver imagens ocultas de nós mesmos, pelas invisibilidades históricas do nosso país.

Na nossa perspectiva, tais corpos da cena e em cena devem ser encarados como 
dotados de força performativa5, uma vez que agenciam a própria percepção e espectatorialidade, incidindo sobre as experiências estéticas:

Em nossa perspectiva, a força da expressão conceitual experiência estética reside na dimensão relacional e articulada aos aspectos simbólicos, políticos e culturais, em suas respectivas materialidades. Sendo assim, o aspecto estético nas experiências emerge sempre que as relações se configuram de modo ordenado, unificado e coerente (mesmo que distante do conceitualmente determinado) (CARDOSO FILHO; GUTMANN, 2019, p. 105).

Isso significa que tais corporalidades nos fazem-fazer, isto é, mais do que representarem, elas performam para/com o corpo do espectador (que, a rigor, é raramente um mero espectador). As próprias ruas são corpos, como escreve Luiz Antônio Simas, ao retomar o pensamento de João do Rio e Walter Benjamin, assim como documentos oficiais e experiências cotidianas na cidade do Rio de Janeiro. "As ruas são como arquivos, verdadeiras bibliotecas da história que pesquiso, escrevo e pela qual sou apaixonado" (2020, p.109), nos conta o historiador. E reivindica: "reencantar a cidade, subverter o território em terreiro, entender a cidade como lugar de encontros" (2020, p.75). Temos aqui um aspecto interessante que nos chama atenção: a relação entre experiência estética e as materialidades envolvidas (seja no ambiente, seja no espaço imaginário) que sempre apresentam singularidades e suas próprias condições de “porosidade” para que a interação se desenvolva.

Nosso exercício constelar se iniciou a partir das condições cotidianas e materiais do isolamento social no Brasil, necessárias para conter o avanço da pandemia de SarsCov-2 (Covid-19), do desejo de expressar as configurações de mútua adaptação encontradas em variados audiovisuais com os quais nos relacionamos ao longo de quase vinte meses de medidas restritivas. Nesse sentido, compreendemos que as constelações que traçamos são modos de performar dos/com os audiovisuais que possibilitam aberturas para encontros imprevisíveis e, possivelmente, transformadores. Trata-se de reencantar os aspaços - tornando-os morada - mesmo aqueles que durante a pandemia, se tornaram ainda mais atravessados por planos multiplicados de trabalho, precariedade e/ou lazer.

\footnotetext{
5 Os performativos foram tipos de proferimentos identificados por John Austin a partir dos quais, ao serem enunciados, realizam-se atos e não apenas constatam-se aspectos do mundo. A partir disso, Austin elaborou sua teoria dos atos de fala, amplamente preocupada com as condições pragmáticas das interações. Ver Austin (1962).
} 


\section{A gira entre mundos pós/pré e pandêmicos}

Contemplando a constelação das encruzilhadas audiovisuais, o que podemos considerar como pontos que vão fazer a gira e o trânsito entre os mundos prépandêmico e pandêmico para o mundo pós-pandêmico? O primeiro desafio que veio já há algum tempo e deve permanecer é justamente a sobreposição destas temporalidades que marcam as gramáticas dos corpos, em uma sensibilidade que vimos buscar no pandêmico, gestos e movimentos do comum pré-pandemico, de resistência, desde o colonial (que segue como nosso fantasma). O reconhecimento dessas sensibilidades outras - entre elas, as amefricanas, ameríndias, na forte relação entre os corpos, ambiente, planos -, que viram no fortalecimento da performance do comum e do cruzo formas de existir e ter ideias para um possível futuro.

As corporalidades audiovisuais - unindo saberes pré e pandêmicos - vão parir outras experiências, distintas das de antes da pandemia, diferentes da do mundo pandêmico, e ainda assim incorporando muito do que foi vivido e imaginado nesses tempos. O plano pré-pandêmico - a imagem como dispositivo de poder, sobretudo no Brasil -, caso que olhamos mais de perto, começou a ganhar novos pontos de vista, pontes, desejo de alteridade em diversos momentos de sua história e, sobretudo, no caso do audiovisual mais recente, com as manifestações coletivas periféricas. Mesmo assim, é preciso fortalecer ainda mais esse gesto. O plano pandêmico, em sua domesticidade, abarca a dimensão das relações entre os sujeitos, os afetos, o comum, o partilhado, entre ambientes e objetos, em planos que privilegiam o relacional, nos corpos em cena e da cena. Mas se uma distancia é minimizada pelas telas, essa proximidade está calcada em novas interações que, por sua vez, criam outras distâncias (CARDOSO FILHO, 2020). No futuro fabulado é preciso estar atento, pois o agora porvir está em devir.

É possível entrever imagens que tendem a evidenciar o discurso contra hegemônico, a partir de realizadores e artistas que entendem que a imagem é poder, em suas relações de visibilidade e invisibilidade. Encarar o audiovisual nessa perspectiva comunitária e de encruzilhada tem se mostrado para nós um movimento de tecer as imagens em relação com outras cosmologias, sobretudo as amefricanas, para que daí possamos compreender constituições de outros imaginários e formas de relação estéticas. A necessidade do cruzo fez ver a importância do desejo pelo outro, da alteridade, que é importante fortalecer no porvir. Dentro do corpus principal de análise, sobretudo os três pontos mais destacados neste momento, a maioria dos 
protagonistas são negros, boa parte dos realizadores são homens negros e mulheres negras, a subjetividade é a do comunitário. Essas imagens emergem a partir do afeto, do pathos, da partilha em intimidade, que aqui é tomada como conjunto de relações de pertencimento que associamos ao filmar em família, em comunidade, gesto que foi conquistando cada vez mais espaço nas formas de experiência do cinema brasileiro (SOUZA, 2017; SOUZA; BOGADO; ALVES JUNIOR, 2020; ALVES JUNIOR; SOUZA; BOGADO, 2021), sobretudo na última década, pelas frestas de um Brasil ainda com fortes ecos coloniais, racistas e machistas.

$\mathrm{Na}$ encruzilhada audiovisual, Exu - princípio de tradução do mundo em linguagens, ambivalência - de forma resiliente e transgressora, mantém acesa a chama que permite imaginar e dialogar outros mundos possíveis, com outras artes, arteiro que é. A partir da formação de nossa constelação inicial, já conseguimos perceber a dimensão do audiovisual como encruzilhada (RUFINO, 2018; SIMAS E RUFINO, 2019), campo de fazer possível o impossível, travessia de espaços/tempos e fortalecimento das práticas comunitárias, em diálogo, afetivas e políticas.

Nas suas múltiplas temporalidades, Exu, dono das encruzilhadas, matou um pássaro ontem com a pedra que atira hoje, ao passo que as luzes das estrelas no céu viajam, ainda agora, por mais de quatro anos para chegar à Terra. Somos tão afetados hoje, pelo que já não está fisicamente próximo, como reescrevemos as experiências que tivemos no passado. Indicamos, por fim, que a constelação "morada”, "abrigo" pode se constituir como uma experiência de reencantamento das vidas ordinárias, pela pulsão dos corpos em fricção, pela construção das frestas, a partir da imaginação e da fabulação.

\section{Referências}

ALVES JUNIOR, Francisco; SOUZA, Scheilla Franca de; BOGADO, Angelita. "O Amor Não Cabe em Um Corpo?”: O Engajamento Espectatorial pela Experiência Familiar/comunitária e Imagens de Libertação. In: CONGRESSO BRASILEIRO DE CIÊNCIAS DA COMUNICAÇÃO, 44.,2021, Virtual. Anais...Virtual: Intercom, 2021. Disponível em https://portalintercom.org.br/anais/nacional2021/resumos/dt7-ep/francisco-alvesjunior.pdf . Acesso em 20 out. 2021.

AUSTIN, John. How to do things with words. $2^{\text {nd }}$ edition. Cambridge/Massachussets: Harvard University Press, 1962.

BOGADO, Angelita; ALVES JUNIOR, Francisco; DE SOUZA, Scheilla Franca. Um estudo sobre performance, dispositivos de regulagem entre formas de vida e formas de imagem no documentário contemporâneo. In: ALMEIDA, G; CARDOSO FILHO, J (Orgs.). 
Comunicação, estética e política: epistemologias, problemas e pesquisas. Curitiba: Editora Appris, 2020, p. 265-280.

; SOUZA, Scheilla Franca de; COIMBRA, Ana Luisa de Castro; ALVES JR, Francisco; CIRINO, Lina. Mergulhar e respirar: cinemas do entrelugar em Ceilândia, Contagem, Recôncavo e a experiência indivisível. 2020. In: LIVE 21 | GT5 CULTURA, COMUNICAÇÃO E ARTES, SENSIBILIDADE E SABERES POPULARES, CONGRESSO INTERNACIONAL DE CULTURAS, 2020, VIRTUA. Disponível em: $<$ https://culturas.cc/congresso2020/16892/>. Acesso em 19 out. 2021.

BRASIL, André. A performance: entre o vivido e o imaginado. In: PICADO, Benjamim; MENDONÇA; Carlos Magno Camargos; CARDOSO FILHO, Jorge. (Org.). Experiência estética e performance. Salvador: EDUFBA, 2014, p. 131-145.

Cineastas guardiões: hipótese sobre autoria no cinema indígena. In: ENCONTRO DA ASSOCIAÇÃO NACIONAL DOS PROGRAMAS DE PÓS-GRADUAÇÃO EM COMUNICAÇÃO (Compós), 30.; GP COMUNICAÇÃO E EXPERIÊNCIA ESTÉTICA, 2021, Virtual. Anais...: Compós, 2021. Disponível em < https://proceedings.science/compos2021/trabalhos/cineastas-guardioes--hipotese-sobre-a-autoria-no-cinema-indigena >. Acesso em 10 jan. 2022.

CARDOSO FILHO, Jorge. Objetos, natureza e cultura: uma proposta de abordagem sobre sensibilidades contemporâneas. In: CARDOSO FILHO, J; ALMEIDA, G; CAMPOS, D (orgs). Políticas do sensível: corpos e marcadores de diferença na Comunicação. Belo Horizonte: Fafich/Selo PPGCOM/UFMG, 2020, p. 297-316.

; GUTMANN, Juliana. Performances como expressões da experiência estética: modos de apreensão e mecanismos operativos. Intexto, Porto Alegre, UFRGS, n. 47, vol. 01, 2019, p. 104-120. Disponível em < https://seer.ufrgs.br/intexto/article/view/81918/53002 >Acesso em 20 jul. 2021.

CORUJA, Paula. Corporalidades produzidas pelo coronavírus: o corpo eletrônico pandêmico. 2020. In: CONGRESSO BRASILEIRO DE CIÊNCIAS DA COMUNICAÇÂO, 43., 2020, Virtual. Anais...Virtual: Intercom, 2020. Disponível em:

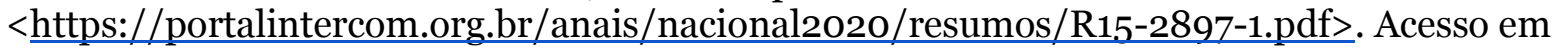
20 out. 2021.

DEWEY, John. Arte como experiência. São Paulo: Martins Fontes, 2010.

MONDZAIN, Marie-José. Imagem, ícone, economia: as fontes bizantinas do imaginário contemporâneo. Rio de Janeiro: Editora Contraponto, 2013.

OTTE, Georg; VOLPE, Míriam Lídia. Um Olhar Constelar Sobre o Pensamento de Walter Benjamin. Fragmentos. Florianópolis, n. 18 , 2000, p. 35-47. Disponível em < https://periodicos.ufsc.br/index.php/fragmentos/article/view/6415 >. Acesso em 10 jan. 2022.

RANCIÈRE, Jacques. A partilha do sensível: estética e política. São Paulo: EXO/ Editora 34, 2009.

RUFINO, Luiz. Pedagogia das encruzilhadas. Rio de Janeiro: Mórula, 2018.

SIMAS, Luiz Antônio; RUFINO, Luiz. Flecha no tempo. Rio de Janeiro: Mórula, 2019. 
2020.

Luiz Antônio. O corpo encantado das ruas. Rio de janeiro: Civilização Brasileira,

SOUTO, Mariana. Constelações fílmicas - um método comparatista no cinema. In: In: ENCONTRO DA ASSOCIAÇÃ̃O NACIONAL DOS PROGRAMAS DE PÓS-GRADUAÇÃO EM COMUNICAÇÃO (Compós), 28., 2019, Porto Alegre. Anais...Porto Alegre: Compós, 2019. Disponível em <https://proceedings.science/compos-2019/papers/constelacoes-filmicas--um-metodo-comparatista-no-cinema> Acesso em 20 out. 2021.

SOUZA, Scheilla Franca de; CARDOSO FILHO, Jorge. Encruzilhadas Audiovisuais: Experiências Estéticas em Tempos de Pandemia e suas Implicações Políticas. In: CONGRESSO BRASILEIRO DE CIÊNCIAS DA COMUNICAÇÂO, 44., 2021, Virtual. Anais...Virtual: Intercom, 2021. Disponível em< https://portalintercom.org.br/anais/nacional2021/resumos/dt7-ep/scheilla-franca-desouza.pdf $>$. Acesso em 20 out. 2021.

. As Ficções de Nós na Filmes de Plástico: reflexividade, intimidade e partilha no cinema brasileiro contemporâneo. Tese (Doutorado em Comunicação e Cultura Contemporâneas), Universidade Federal da Bahia, Salvador, 2017.

; BOGADO; Angelita; ALVES JUNIOR, Francisco. Ela, Ele e Person: Invisibilidades e Resistência no Cinema Brasileiro Contemporâneo. In: CONGRESSO BRASILEIRO DE CIÊNCIAS DA COMUNICAÇÂO, 43., 2020, Virtual. Anais...Virtual: Intercom, 2020. Disponível em $<$ https://portalintercom.org.br/anais/nacional2021/resumos/dt7-ep/scheillafranca-de-souza.pdf $>$. Acesso em 20 out. 2021.

Este é um ARTIGO publicado em acesso aberto (Open Access) sob a licença Creative Commons Attribution, que permite uso, distribuição e reprodução em qualquer meio, sem restrições, desde que o trabalho original seja corretamente citado. 